\title{
Conducting Polymer Composites: Polypyrrole and Poly (vinyl chloride-vinyl acetate) Copolymer
}

\author{
NURCAN BALCI, ${ }^{1}$ ERDAL BAYRAMLI, ${ }^{1}$ LEVENT TOPPARE ${ }^{2}$ \\ ${ }^{1}$ Department of Chemistry, Middle East Technical University, 06531 Ankara, Turkey \\ ${ }^{2}$ Department of Chemistry, Bilkent University, 06533 Ankara, Turkey
}

Received 27 May 1996; accepted 7 August 1996

\begin{abstract}
Composites of a polypyrrole (PPy) and poly (vinyl chloride-vinyl acetate) copolymer (PVC-PVA) were prepared both chemically and electrochemically. An insulating polymer was retained in the blend and the thermal stability of the polymer was enhanced by polymerizing pyrrole into the host matrix in both cases. The composites prepared electrochemically gave the best results in terms of conductivity and air stability. (C) 1997 John Wiley \& Sons, Inc. J Appl Polym Sci 64: 667-671, 1997
\end{abstract}

\section{INTRODUCTION}

The conductivity and stability of organic conducting polymers have been largely improved, but for practical purposes, there exist several difficulties because of their poor mechanical properties. Several attempts have been made to overcome this problem, one of which was the synthesis of composites, where the conductivity of the conducting polymer is combined with the mechanical properties of the matrix polymer. Composites can be prepared chemically or electrochemically. The first attempt of chemical preparation of polypyrrole (PPy) as a polymeric composite was reported by Bjorklund and Lundstroom. ${ }^{1}$ Polypyrrole as a conductive polymer was electrochemically synthesized for the first time by Weiss et al. in $1965^{2}$ and later studied by Diaz et al. ${ }^{3}$ Potentiostatic anodic polymerization of pyrrole in acetonitrile containing a tetraalkylammonium salt was used to obtain conductive PPy films. In the meantime, many studies have been done to obtain stable, processable, and conductive polymeric materials. $^{4-8}$

Correspondence to: L. Toppare.

(C) 1997 John Wiley \& Sons, Inc. CCC 0021-8995/97/040667-05
In this article, we describe the preparation and characterization of a PPy/poly (vinyl chloride-vinyl acetate) (PPy/PVC-PVA) composite by both chemical and electrochemical methods, with the simple expectation that the composites should have better mechanical properties compared to pure PPy. The retainment of conductivity, on the other hand, should reveal conducting polymer composites. This argument very much depends on the type of insulating polymer used in the electrochemical blending process. ${ }^{6}$ With suitable polymers, percolation thresholds as low as $7 \%$ of the insulating polymer content can be achieved with little loss in conductivity.

\section{EXPERIMENTAL}

For the synthesis of the PPy composite with PVCPVA which has $10 \%$ PVA content, an in situ polymerization technique was used. This was carried out by introducing pyrrole into the polymer matrix (VC-VA) followed by a treatment with an oxidant solution. Iron(III) chloride was used as the oxidant and THF was chosen as the solvent. After the casting and the polymerization reaction were completed, films were dried in a vacuum and kept under a nitrogen atmosphere. 
PPy/PVC-PVA composites were prepared by the electrochemical polymerization of pyrrole onto a PVC-PVA-coated electrode. A 2\% VC-VA solution in THF was used for the coating of the platinum electrode. The monomer concentration was $0.025 \mathrm{M}$, the electrolyte was tetrabutylammonium tetrafluoroborate (TBAFB), and the solvent was acetonitrile. The Pt working electrode was maintained at $1.1 \mathrm{~V}$ vs. a $\mathrm{Ag} / \mathrm{Ag}^{+}$reference electrode. The electrolysis time was about $15-20 \mathrm{~min}$ and the drying temperature of the films was $50^{\circ} \mathrm{C}$. The amounts of insulating and conducting polymer coatings were determined gravimetrically. The details of potentiostatic electrolysis were previously given elsewhere. ${ }^{6,7}$

FTIR studies were conducted to investigate the presence of both polymers in the blend. FTIR spectra of polymers and composites were recorded on a Nicolet 510 FTIR spectrophotometer with KBR pellets at a $2 \mathrm{~cm}^{-1}$ resolution.

Conductivity measurements were made at room temperature using the standard four-probe technique in which a constant current source is used to pass a steady current through the outermost probes and the voltage drop across the inner two is measured. ${ }^{8}$

Mechanical testing of films were done by an Instron TM 1102 tensile testing machine with a $0.31 \mathrm{~mm} / \mathrm{min}$ crosshead speed at ambient temperature. All composites were tested several times (three to four). Sample sizes were $3.5 \mathrm{~cm}$ to $2.9 \mathrm{~mm}$.

Differential scanning calorimetry studies were carried out under a $\mathrm{N}_{2}$ atmosphere using a TA Instruments Thermal Analyst 2000 System. The heating rate was $10^{\circ} \mathrm{C} / \mathrm{min}$. The data presented represent the first run for all cases.

\section{RESULTS AND DISCUSSION}

In situ polymerization of pyrrole with the VCVA copolymer leads to formation of black films. The FTIR spectra of the composite and the polymer were investigated. The FTIR spectra of the $\mathrm{PPy} / \mathrm{PVC}-\mathrm{PVA}$ composite reveals that the insulating polymer was retained in the blend. Some of the characteristic peaks $\left(\mathrm{cm}^{-1}\right)$ of the composite are a $\mathrm{C}-\mathrm{Cl}$ band at 695 , a $\mathrm{C}-\mathrm{N}$ band at 1100 , a $\mathrm{C}-\mathrm{C}$ band at 1238 , a $\mathrm{C}=\mathrm{O}$ stretching band at 1740 , and a $\mathrm{C}-\mathrm{H}$ stretching band of PVC-PVA at 2970 . A different peak which was observed only

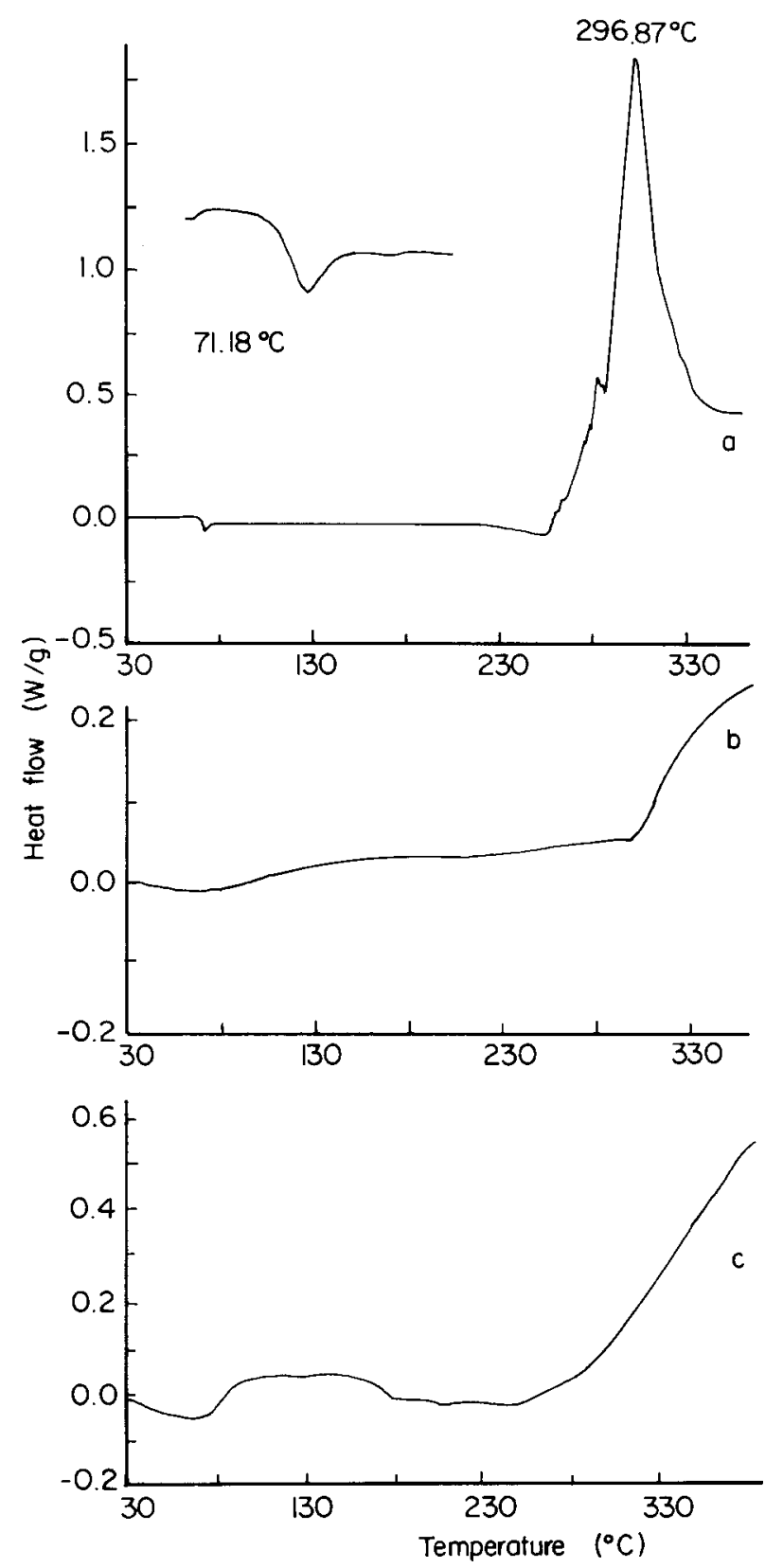

Figure 1 DSC of (a ) PVC-PVA, (b) PPy/PVC-PVA composite prepared chemically, and (c) PPy/PVC-PVA composite prepared electrochemically.

for electrochemical composites was at $1080 \mathrm{~cm}^{-1}$, which is assigned to the dopant anion $\left(\mathrm{BF}_{4}^{-}\right)$.

The glass transition temperature of the copolymer (PVC-PVA) is $71^{\circ} \mathrm{C}\left(T_{g}\right)$ and it melts at $296^{\circ} \mathrm{C}\left(T_{m}\right)$. Above $300^{\circ} \mathrm{C}$, degradation takes place, which can be seen from Figure 1. Thermal behaviors of electrochemical and chemical composites are similar. The thermal stability of the 


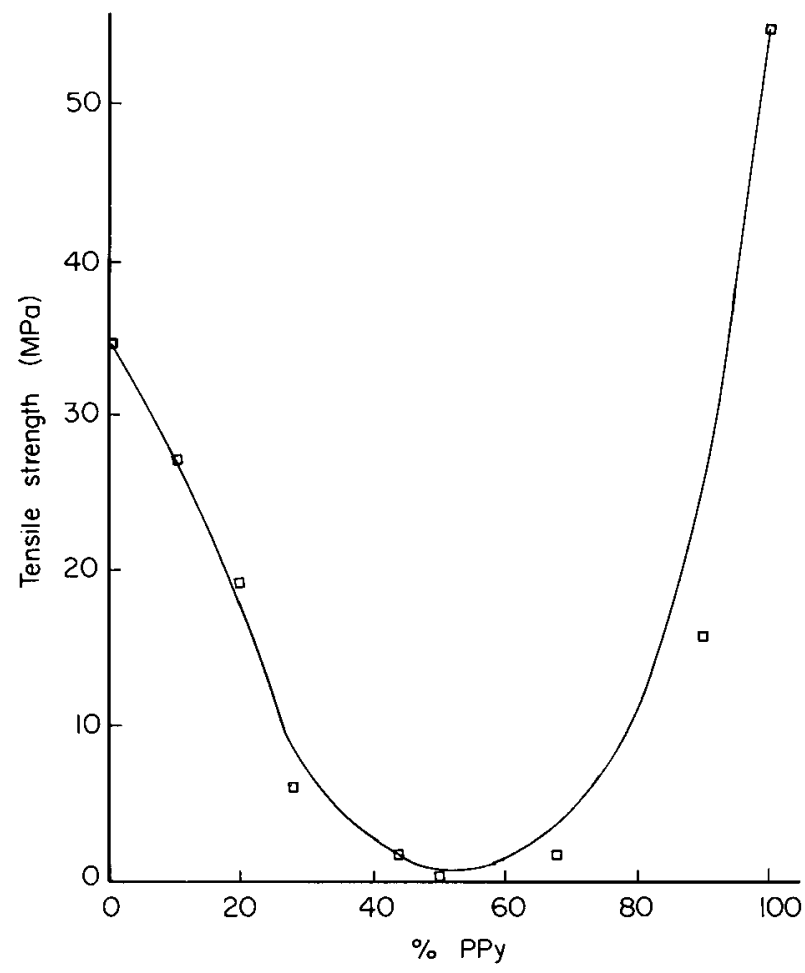

Figure 2 Maximum tensile strength vs. \% PPy content of chemically produced PPy/PVC-PVA composites.

polymer was enhanced by the formation of a composite structure.

Mechanical tests showed that PPy and PVCPVA are not compatible. There was a certain decrease in the tensile strength for an increasing percentage of PPy up to one point and then an increase was observed (Fig. 2).
Table I Conductivities of the Films Obtained by Anodic Oxidation of PPy

\begin{tabular}{rcc}
\hline$\% \mathrm{PPy}$ & $\begin{array}{c}\text { Conductivity of } \\
\text { Solution Side } \\
(\mathrm{S} / \mathrm{cm})\end{array}$ & $\begin{array}{c}\text { Conductivity of } \\
\text { Electrode Side } \\
(\mathrm{S} / \mathrm{cm})\end{array}$ \\
\hline 32 & 0.01 & 0.2 \\
43 & 3 & 9.8 \\
50 & 4 & 10.5 \\
90 & 6 & 18 \\
100 & 20 & 20 \\
\hline
\end{tabular}

This is a sign of incompatibility since both pristine polymers yield higher tensile strengths compared to the composite concerned. The maximum percent elongation of the composite gave almost a constant value around 3\% (Fig. 3). It was not possible to determine the same parameters for the electrochemically prepared composite since we were restricted by the electrode size.

The conductivities of the chemically prepared composite films are between $10^{-4}$ and $10^{-3} \mathrm{~S} / \mathrm{cm}$ and the air stability is very low. The conductivities of electrochemically prepared films are given in Table I.

The conductivities of the solution side and that of the electrode side of the films were different. There exists a threefold increase in the conductivities of the electrode side of the composite films containing PPy above $40 \%$ with respect to the conductivities of solution sides (Fig. 4). An important difference lies in the conductivities of the composites. The conductivity of the PPy/PVC-PVA composite prepared electrochemically is environmen-

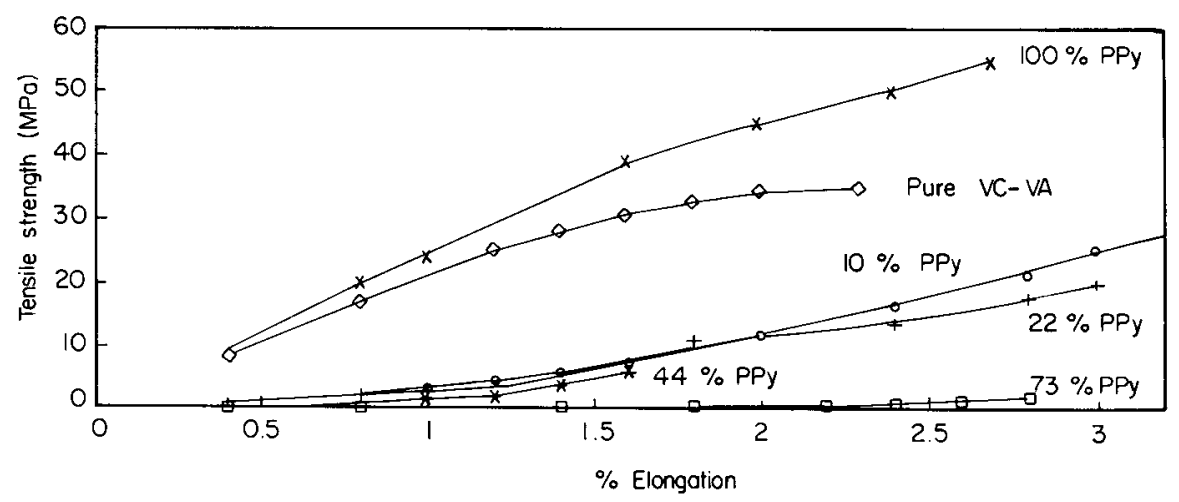

Figure 3 Tensile strength vs. \% elongation curves of chemically produced PPy/PVCPVA composites for several PPy contents. 


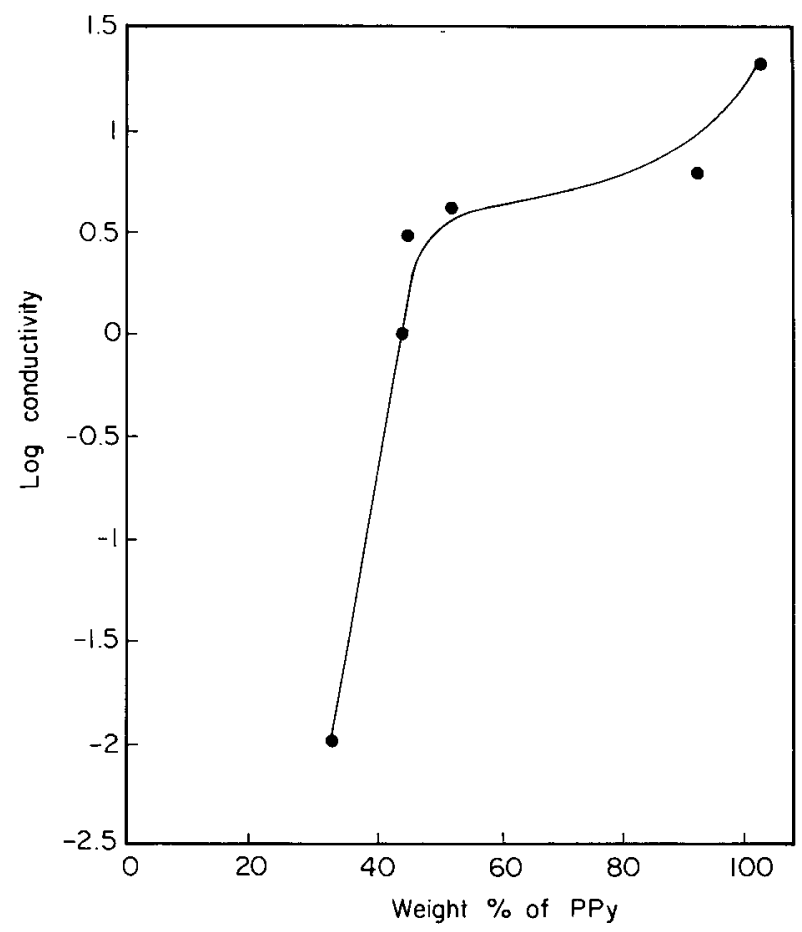

Figure 4 Weight \% vs. log conductivity of solution side of PPy/PVC-PVA (prepared electrochemically).

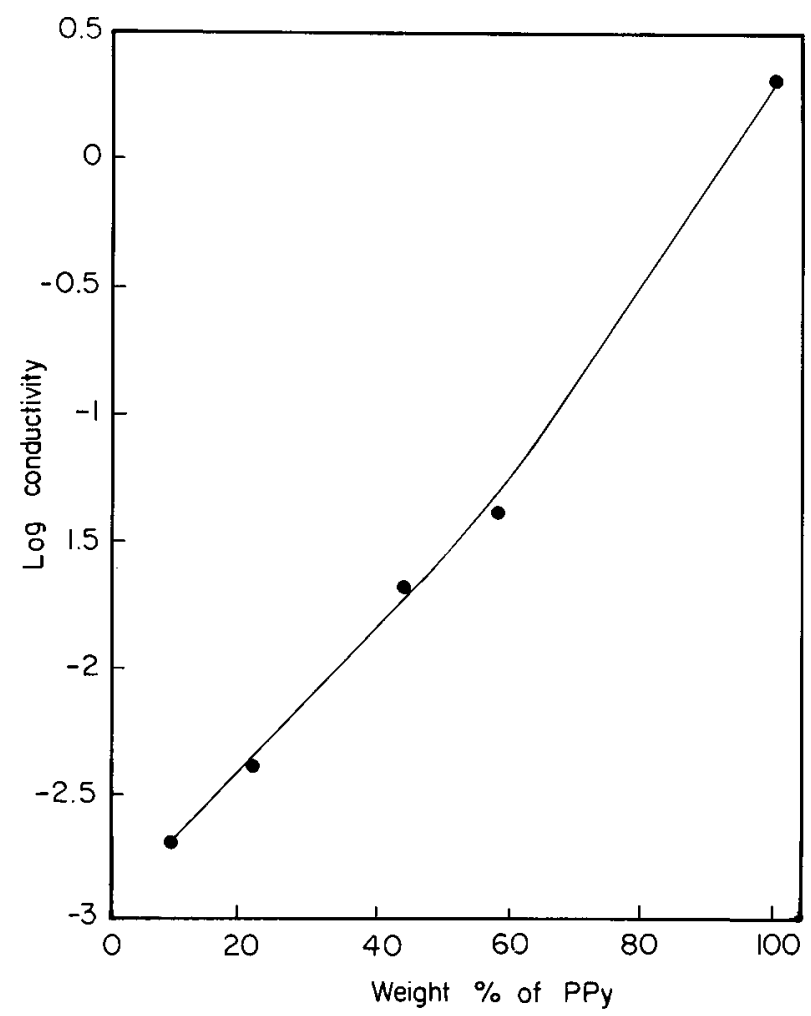

Figure 5 Weight \% vs. log conductivity of PPy/PVCPVA (prepared chemically).
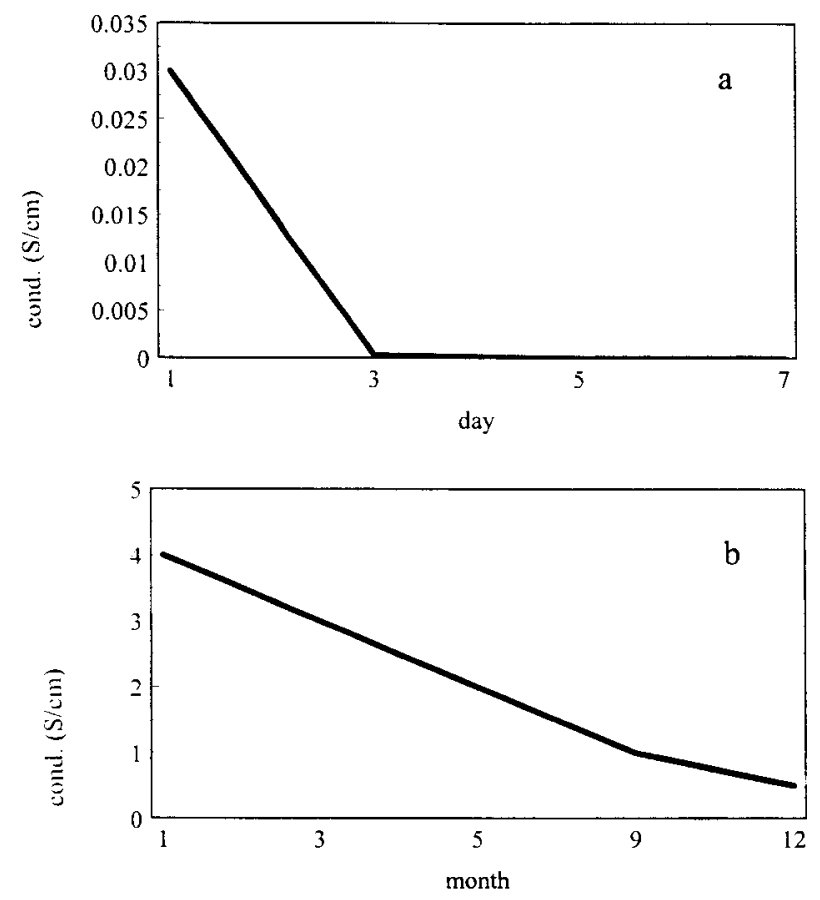

Figure 6 Conductivity vs. time graphs for (a) chemically prepared PPy/PVC-PVA ( $50 \%$ by PPy) and (b) electrochemically prepared PPy/PVC-PVA (50\% by PPy).

tally stable. Threshold conductivities near $40 \%$ were observed for the electrolytic composite. Above the threshold concentration (40\% PPy), conductivity is not affected much by the amount of the conducting polymer; however, there exists a steeper rise in the conductivity up to the threshold concentration.

On the other hand, there is no threshold value in the chemically prepared composite (Fig. 5). While chemically prepared composites lose their conductivity in 1 week, electrolytic composites are still conducting after 1 year (Fig. 6 ).

\section{CONCLUSION}

The thermal stability of the PVC-PVA copolymer was enhanced by making the composite with PPy. The electrochemically prepared PPy/PVC-PVA composite is a film-forming conducting material with a threshold conductivity at $40 \% \mathrm{PPy}$ and its air stability is very good. However, the chemically prepared composite loses its conductivity in 1 week. Therefore, the electrochemical method is 
more advantageous in terms of conductivity and air stability.

\section{REFERENCES}

1. R. B. Bjorklund and I. Lundstroom, J. Electron. Mater., 13, 211 (1984).

2. R. Mac Neill, D. E. Weiss, and D. Willist, Aust. J. Chem., 18, 477 (1965).
3. A. F. Diaz, K. K. Kanazawa, and G. P. Gardini, J. Chem. Soc. Chem. Commun., 635 (1979).

4. M. A. De Paoli, Quim. Nova, 9, 133 (1986).

5. N. Balc1, E. Bayraml, and L. Toppare, Composites, 26, 229 (1995).

6. H. L. Wang, J. E. Fernandez, and L. Toppare, Macromolecules, 23, 1053 (1990).

7. S. Doğan, U. Akbulut, and L. Toppare, Syn. Met., 53, 29 (1990).

8. F. Selampınar, U. Akbulut, T. Yalçın, Ş. Süzer, and L. Toppare, Syn. Met., 62, 201 (1994). 